\title{
Physiotherapeutic interventions in multiple sclerosis across Europe: Regions and other factors that matter is
}

\author{
Patrícia Martinkováa, ${ }^{\mathrm{a}}$, Jenny Freeman ${ }^{\mathrm{b}}$, Adéla Drabinovác, Elena Erosheva ${ }^{\mathrm{d}}$, Davide Cattaneo ${ }^{\mathrm{e}}$, \\ Johanna Jonsdottirf ${ }^{\mathrm{f}}$ Ilse Baert ${ }^{\mathrm{g}}$, Tori Smedal ${ }^{\mathrm{h}}$, Anders Romberg ${ }^{\mathrm{i}}$, Peter Feys ${ }^{\mathrm{j}}$, Jose Alves-Guerreiro ${ }^{\mathrm{k}}$,
} Mario Habek $^{1}$, Thomas Henze ${ }^{\mathrm{m}}$, Carme Santoyo Medina ${ }^{\mathrm{n}}$, Antonie Beiske ${ }^{\circ}$, Paul Van Asch ${ }^{\mathrm{p}}$, Daphne Bakalidou ${ }^{\mathrm{q}}$, Yeliz Salcir ${ }^{\text {r }}$ Erieta Nikolikj Dimitrovas ${ }^{\text {s }}$ Markéta Pavlíkovát, Kamila Řasováu

${ }^{a}$ Department of Statistical Modelling, Institute of Computer Science, Czech Academy of Sciences, Czech Republic

${ }^{\mathrm{b}}$ Faculty Health and Human Sciences, Plymouth University, Devon PL68BH, United Kingdom

${ }^{c}$ Department of Statistical Modelling, Institute of Computer Science, Czech Academy of Sciences, and Faculty of Mathematics and Physics, Charles University, Czech Republic

${ }^{d}$ Department of Statistics, School of Social Work, and the Center for Statistics and the Social Sciences, University of Washington, Seattle, USA

e Don Gnocchi Foundation, IRCCS Milan, Larice Lab, Via Capecelatro 66, 20148 Milan, Italy

${ }^{\mathrm{f}}$ Don Gnocchi Foundation, Larice Lab, IRCCS Milan, Via Capecelatro 66, 20148 Milan, Italy

${ }^{g}$ Hasselt University, Campus Diepenbeek, REVAL, BIOMED-Biomedical Research Institute, Faculty of Medicine and Life Sciences, Hasselt University, Hasselt, Belgium

${ }^{\mathrm{h}}$ Norwegian Multiple Sclerosis Competence Centre, Department of Neurology, and Department of Physiotherapy, Haukeland University Hospital, P.O.Box 1400, 5021 Bergen, Norway

i Masku Neurological Rehabilitation Centre, Physiotherapy, Vaihemäentie 10, PO Box 15, 21251 Masku, Finland

${ }^{\mathrm{j}}$ Hasselt University, Campus Diepenbeek, REVAL Rehabilitation Research Institute (BIOMED), Agoralaan building A, B-3590 Diepenbeek, Belgium

${ }^{\mathrm{k}}$ School of Health Sciences, Health Research Unit, Polytechnic Institute of Leiria, Campus 2 - Morro do Lena - Alto do Vieiro, 2411-901 Leiria, Portugal

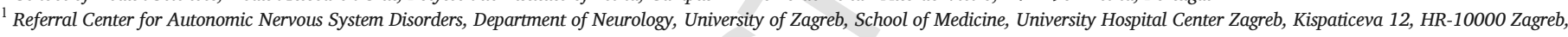
Croatia

m PASSAUER WOLF Reha-Zentrum Nittenau, Rehabilitations-klinik für Neurologie-Geriatrie-Urologie, Eichendorffstr. 21 D-93149 Nittenau, Germany

${ }^{\mathrm{n}}$ Neurology-Neuroimmunology Department \& Neurorehabilitation Unit. Multiple Sclerosis Centre of Catalonia (Cemcat) Pg. Vall d'Hebron 119-129. 08035, Barcelona, Spain

Nevrologgruppen Oslo. Lillegrensen 7, N-0159 Oslo, Norway

${ }^{\mathrm{p}}$ Fit Up, Fitness, and Physiotherapy Center, Mechelsesteen weg 192a, 2550 Kontich, Belgium

${ }_{\mathrm{q}}^{\mathrm{q}}$ Technological Educational Institute of Athens, 24, Mitrodorou street, 10441 Ak. Pratonos, Athens, Greece

${ }^{\mathrm{r}}$ Hacettepe University, Faculty of Health Science, Department of Physical Therapy and Rehabilitation, Ankara, Turkey

${ }^{s}$ Institute of Physical Medicine and Rehabilitation, Faculty of Medicine, "Ss Cyril and Methodius" University, Elisie Popovski 28, 1000, Skopje, The former Yugoslav Republic of Macedonia (FYROM)

t Third Faculty of Medicine, Charles University, Ruska 87, Prague 10, 100 00, Czech Republic

u Department of Rehabilitation, Third Faculty of Medicine, Charles University, Ruska 87, Prague 10, 100 00, Czech Republic

\section{A R T I C L E I N F O}

Keywords:

Multiple sclerosis

Physical therapy

Physiotherapeutic interventions

Europe

Questionnaire survey

Cluster analysis

\section{A B S T R A C T}

Background: A wide variety of interventions exists in physical therapy (PT), but knowledge about their use across different geographical regions is limited. This study investigated the use of PT interventions in people with Multiple Sclerosis (MS) across Europe. It aimed to determine whether regions differ in applying interventions, and explore whether factors other than regions play a role in their use.

Methods: In an online cross-sectional survey, 212 respondents from 115 European workplaces providing PT services to people with MS representing 26 countries (four European regions) participated. Cluster analysis, Pearson Chi-squared test and a Poisson regression model were used to analyze the data.

Abbreviations: MS, Multiple Sclerosis; PT, Physical Therapy; PTs, Physical Therapists; ICF, International Classification of Functioning, Disability and Health; RIMS, European network for best practice and research in MS Rehabilitation.

h Core group of Special interest group in mobility, Rehabilitation in Multiple Sclerosis, the European network for best practice and research in MS Rehabilitation (www.eurims.org).

* Correspondence to: Department of Statistical Modelling Institute of Computer Science, Czech Academy of Sciences Pod Vodárenskou věží 2, Prague 8, 192 07, Czech Republic.

Email addresses: martinkova@cs.cas.cz (P. Martinková); jenny.freeman@plymouth.ac.uk (J. Freeman); drabinova@cs.cas.cz (A. Drabinová); erosheva@uw.edu (E. Erosheva);

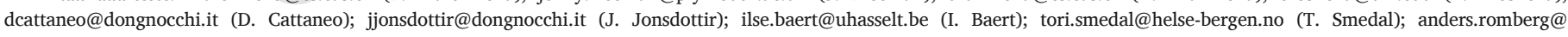

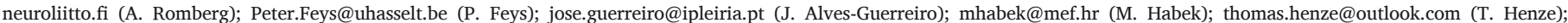

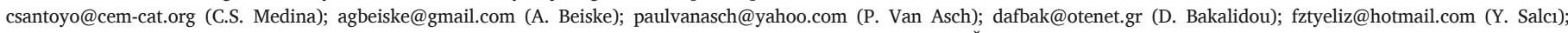
erietand@yahoo.com (E.N. Dimitrova); pavlikova@biostatisticka.cz (M. Pavlíková); kamila.rasova@gmail.com (K. Řasová) 
Results: Thirteen of 45 listed PT interventions were used by more than $75 \%$ of centers, while nine interventions were used by less than 25\%. For 12 interventions, regions differed markedly in their use. Cluster analysis of centers identified four clusters similar in their intervention use. Cluster assignment did not fully align with regions. While center region was important, center size, number and gender of physical therapists working in the center, and time since qualification also played a role. Cluster analysis exploring the use of the interventions provided the basis for a categorization of PT interventions in line with their primary focus: 1. Physical activity (fitness/ endurance/resistance) training; 2. Neuroproprioceptive "facilitation/inhibition"; 3. Motor/skill acquisition (individualized therapy led); 4. Technology based interventions.

Conclusions: To our knowledge this is the first study that has explored this topic in MS. The results broaden our understanding of the different PT interventions used in MS, as well as the context of their use.

\section{Introduction}

In the last decade, the number of published studies on physical rehabilitation in multiple sclerosis (MS) including physical therapy (PT) and exercise therapy has steadily increased, providing a more solid evidence-base for this area (Dalgas et al., 2010; Gijbels et al., 2011; Freeman et al., 2012; Carpinella et al., 2012; Latimer-Cheung et al., 2013; Baert et al., 2014; Kjolhede et al., 2015; Sandroff et al., 2017; Heine et al., 2017; Motl et al., 2017). Evidence shows that PT interventions can lead to clinically meaningful improvements in all categories defined by the International Classification of Functioning, Disability and Health (ICF) (Khan and Pallant, 2007; Kesselring et al., 2008).

PT comprises a wide variety of interventions based on different philosophical approaches. A range of factors, including the country's culture, models of training and education, and health care system can all influence whether and how interventions are adopted for use within clinical practice (Rasova et al., 2010). Understanding the content and delivery of these interventions across different countries is important to enhance translation of results to practice. Despite this, knowledge is limited about whether these interventions are used systematically and according to evidence-based practice. Hence, in response to this, a project was designed to gather information about the use of PT interventions across Europe. Previous articles have described project results pertaining to the organizational aspects of physiotherapy for people with MS across Europe (Rasova et al., 2016, 2014). This article focuses on detailing the PT interventions used by the centers, to determine whether, and if so how, regions differ in the therapeutic methods utilized.

\section{Methods}

Methods of the project COPHYREQUEST have been previously described (Rasova et al., 2016). This article presents the results of the second phase of the project in which physical therapists (PTs) who work with MS patients were asked to describe the content of PT they offer to their patients. Responses of individual PTs were then used to describe the content of PT offered by their workplace to the MS patients.

\subsection{Research design}

A descriptive, cross-sectional on-line survey, using convenience sampling was used.

\subsection{Recruiting process}

Key individuals from 28 countries working in the field of MS rehabilitation, according to their best knowledge and experience, identified 202 facilities/workplaces, which provide PT services for people with MS (Rasova et al., 2016). PTs from these workplaces were asked to participate. In addition, the survey was advertised on the webpage of the European network for best practice and research in MS Rehabilitation (RIMS) www.eurims.org, and promoted in RIMS workshops and conferences.

\subsection{Survey on the use of PT interventions}

An internet-based survey on the content of PT in MS patients was developed, using in iterative process by a core-working group (Rasova et al., 2010, 2016, 2014). The survey was nine pages long and covered respondent characteristics, PT interventions offered to their patients, goal setting, length and setting of PT, functions assessed and assessment instruments used. In this article we analyze the first two sections of the survey.

The first section of the survey asked about respondent characteristics: gender, age category, highest level of education, years of PT practice, work time spent with MS patients, workplace (center) and e-mail (voluntary). In the second section of the survey, respondents were asked to choose, on a five-point Likert scale (Never, Rarely, Sometimes, Often, and Almost Always), how often they offered the 45 listed PT interventions (Table 1 ) to their MS patients. A list of PT interventions was prepared by the core group based on an extensive literature review with the goal of covering all PT interventions used with MS patients. Besides, respondents had the option to list "Other" PT interventions they use for their patients. A vocabulary of listed PT interventions was provided (Supplemental Table 1).

\subsection{Categorization of interventions}

In our previous commentary (Rasova et al., 2010), three categories of PT interventions were defined according to three motor control theories (Shumway-Cook, 2006): 1 = muscle re-education; 2 = neuroproprioceptive facilitation; 3 = task oriented approach. The fourth category $4=$ use of special technology or environment was added on the basis of expert consensus.

Twenty specialists within the field formed a core-working group, with the remit of classifying the listed interventions into these four categories (Supplemental Table 2, column "Initial categories"). This initial classification was used for data analysis.

Results of the statistical analyses (see below), together with an iterative process (consensus gained through face-to-face discussion and two rounds of email communication between members of the core group) led to reformulation of these into four categories which were considered to hold more resonance with clinical practice, and which are presented in this article (see Discussion and Supplemental Table 2, column "Final categories").

\subsection{Data analyses}

Countries were divided into four European regions, defined by the United Nations Statistics Department (Department UNS). A center was said to "use the given PT intervention" if at least one of the respondents declared they used it "Sometimes", "Often" or "Almost Always".

Polychoric correlation was used to assess similarities between PT interventions based on their patterns of use by the centers. Clusters of PT interventions commonly used were identified using a hierarchical clustering approach with the distance based on polychoric correlations 
Table 1

List of PT interventions, as described and ordered in the online survey.

\begin{tabular}{|c|c|}
\hline $\begin{array}{l}\text { Intervention } \\
\text { short name }\end{array}$ & $\begin{array}{l}\text { Interventions as described and ordered in the online } \\
\text { survey }\end{array}$ \\
\hline Aerobic & Aerobic training, conditioning exercises \\
\hline Breathing & $\begin{array}{l}\text { Breathing exercise, e.g. expiratory muscle training, } \\
\text { respiratory muscle training }\end{array}$ \\
\hline Strengthening & Strengthening, resistance training \\
\hline Stretching & Muscle stretching \\
\hline Balance & Balance training (static, dynamic), postural awareness \\
\hline Transfer & Training for transfers and ambulatory abilities \\
\hline Daily & Training for other activities of daily living \\
\hline Dual & Dual tasking \\
\hline Orthotics & $\begin{array}{l}\text { Biomechanical approaches (e.g. hip flexion assistance } \\
\text { device, ankle foot orthosis) }\end{array}$ \\
\hline Biofeedback & $\begin{array}{l}\text { Modality intervention, e.g. biofeedback, functional } \\
\text { electrical stimulation, pulse magnetic field therapy, TENS }\end{array}$ \\
\hline Cryotherapy & Cryotherapy (local or general) \\
\hline Heat & Heat therapy \\
\hline Self-care & $\begin{array}{l}\text { Professionally guided self-care, lifestyle changes, coping } \\
\text { skills, education of patients or carers }\end{array}$ \\
\hline Fatigue & $\begin{array}{l}\text { Fatigue management program, energy conservation on } \\
\text { fatigue }\end{array}$ \\
\hline Pain & Pain control \\
\hline Cognitive & Cognitive, visual and sensory perceptual training \\
\hline Stimulation & Sensory stimulation \\
\hline Vojta & Vojta reflex locomotion \\
\hline Brunnstrom & Brunnstrom approach \\
\hline Bobath & Bobath concept \\
\hline PNF & Proprioceptive neuromuscular facilitation \\
\hline Perfetti & Perfetti approach \\
\hline Motor learning & Motor learning program \\
\hline Brügger & Brügger concept \\
\hline Frenkel & Frenkel's exercise \\
\hline Feldenkrais & Feldenkrais method \\
\hline Conductive & Conductive education programme \\
\hline Constraint & Constraint-induced movement therapy \\
\hline Rood & Rood's approach \\
\hline Pelvic & Pelvic floor exercise \\
\hline Hippotherapy & Hippotherapy \\
\hline Aquatherapy & Aquatherapy \\
\hline Nordic & Nordic walking \\
\hline Music & Music therapy, dance therapy \\
\hline Manual & Manual therapy \\
\hline Proprioneuro & Proprioneuro-physiolgical methods \\
\hline Mechanotherapy & Mechanotherapy \\
\hline Relaxation & Relaxation techniques \\
\hline Oriental & Oriental methods \\
\hline Robotic & $\begin{array}{l}\text { Robotic-assisted rehabilitation therapy (e.g. Lokomat }{ }^{\circledR} \text {, } \\
\text { Armeo®) }\end{array}$ \\
\hline $\begin{array}{l}\text { Gaming } \\
\text { technology }\end{array}$ & Sensor assisted rehabilitation (e.g. Wii, Kinect) \\
\hline Treadmill & $\begin{array}{l}\text { Devices for walking (e.g. Treadmill, Body weight support } \\
\text { system) }\end{array}$ \\
\hline Balance platform & $\begin{array}{l}\text { Devices for proprioceptive posture therapy (e.g. 3D } \\
\text { Spacecurl, POSTUROMED®, vibration platform) }\end{array}$ \\
\hline Simple & $\begin{array}{l}\text { Simple devices (e.g. kinesio-tape, overball, mirror, thera- } \\
\text { band, splints, standing frame) }\end{array}$ \\
\hline Pharmacotherapy & Pharmacotherapy combined with therapy \\
\hline
\end{tabular}

and Ward's linkage (Ward, 1963). The optimal number of clusters was decided based on an inspection of the scree plot (Mardia and Bibby, 1979; BD VWaR, 2002).

Similarly, a polychoric correlation matrix between centers was undertaken, using the same approach described above, to further study the differences and similarities between centers based on their patterns of the PT interventions use and to identify clusters of similar centers.

Differences between regions or clusters were assessed through Pearson Chi-squared test with a simulated p-value (Hope, 1968). For multiple comparisons, Benjamini-Hochberg correction (Y BYaH, 1995) was applied. We used the simulated value because in some cells, there are very small counts. In case of high numbers in cells, the results are similar to those using classical Chi-squared test, we used the simulated p-value for consistency.
To model the number of used methods by center Poisson regression model was used, i.e. generalized linear regression with log link (A A, 2013). Center size, MS ratio, MS inpatient ratio, number of respondents, maximum years of practice of respondents, maximum work time with MS patients, minimum education and gender proportion of respondents in each center were considered as possible covariates. The significance of factors was determined by the likelihood ratio test of the corresponding sub-model.

For all analyses, the level of statistical significance was set at 0.05. Statistical language and environment $R$, version 3.4.0, (Team, 2017) was used throughout the analyses.

\section{Results}

\subsection{Characteristic of participants}

Of the 277 workplaces approached, 212 respondents from 115 European workplaces, representing 26 countries from four European regions participated in the study (center response rate 42\%). On average, two representatives per center, who were PTs specialized in MS, completed the questionnaire (Table 2).

Half of the workplaces were small centers who provided PT for up to 100 patients a year, while over two thirds had a small ratio (up to $20 \%$ ) of MS patients. The regions had similar composition of centers in size, MS ratio, as well as percentage of inpatients/outpatients and PTs' proportion of work time spent with MS patients (Table 3).

\section{2. $P$ T interventions used in $M S$}

Thirteen of the 45 listed interventions were used by more than $75 \%$ of centers, while nine interventions were used by less than $25 \%$ of centers (Table 4).

\subsection{Use of PT interventions in different European regions}

The four European regions significantly differed in the use of 12 PT interventions (Table 4). For example, the Vojta reflex locomotion is the prevailing intervention in countries sited within the Eastern region, but is not used in the other regions. In contrast, fatigue management was reported as being used in all of the Western centers but is much less used in countries within the Eastern or Southern regions (Fig. 1). Moreover, significant differences $(\mathrm{p}=0.049)$ appear in the proportions of categories of PT interventions used (Fig. 2), for example, Eastern countries seem to use more neuroproprioceptive facilitation interventions, while Northern and Western countries utilize more special tools/devices.

\subsection{Number of PT interventions according to region, number of physical therapists and their specialization, experience and education}

Centers employing more therapists, and more highly experienced therapists, used a wider variety of PT interventions. PTs with a PhD qualification utilized a smaller variety of interventions, whilst more clinically experienced PTs and those whose patient sample comprised a greater proportion of people with MS reported using a wider variety of interventions. Centers from the Northern region used a significantly narrower variety of interventions than those from Eastern regions (Supplemental Table 3).

\subsection{Clusters of PT interventions}

Correlations between use of PT interventions lead to seven clusters of interventions which were usually reported to be used together (Figs. 3 and 4, Supplemental Table 2). Further description of clusters is provided in the discussion section, together with a proposed updated clas- 
Table 2

Survey participants.

\begin{tabular}{|c|c|c|c|c|}
\hline & Centers approached $[\mathrm{N}]$ & Centers participating $[\mathrm{N}]$ & Center response rate $[\%]$ & Respondents [N] \\
\hline \multicolumn{5}{|l|}{ East } \\
\hline Czech Republic & 24 & 13 & 54.17 & 26 \\
\hline Poland & 13 & 1 & 7.69 & 5 \\
\hline Romania & 3 & 1 & 33.33 & 3 \\
\hline Slovakia & 5 & 1 & 20.00 & 1 \\
\hline Total & 45 & 16 & 35.56 & 35 \\
\hline \multicolumn{5}{|l|}{ North } \\
\hline Denmark & 2 & 1 & 50.00 & 7 \\
\hline Estonia & 3 & 2 & 66.67 & 4 \\
\hline Finland & 6 & 2 & 33.33 & 10 \\
\hline Ireland & 12 & 4 & 33.33 & 4 \\
\hline Norway & 18 & 7 & 38.89 & 10 \\
\hline Sweden & 19 & 12 & 63.16 & 19 \\
\hline United Kingdom & 20 & 9 & 45.00 & 11 \\
\hline Total & 80 & 37 & 46.25 & 65 \\
\hline \multicolumn{5}{|l|}{ South } \\
\hline Croatia & 6 & 3 & 50.00 & 14 \\
\hline FYROM & 6 & 2 & 33.33 & 4 \\
\hline Greece & 6 & 2 & 33.33 & 2 \\
\hline Italy & 26 & 24 & 92.31 & 25 \\
\hline Portugal & 10 & 5 & 50.00 & 11 \\
\hline Serbia & 7 & 3 & 42.86 & 14 \\
\hline Slovenia & 6 & 3 & 50.00 & 6 \\
\hline Spain & 22 & 8 & 36.36 & 14 \\
\hline Turkey & 8 & 1 & 12.50 & 1 \\
\hline Total & 97 & 51 & 52.58 & 91 \\
\hline \multicolumn{5}{|l|}{ West } \\
\hline Austria & 18 & 1 & 5.56 & 1 \\
\hline Belgium & 7 & 3 & 42.86 & 10 \\
\hline France & 9 & 2 & 22.22 & 3 \\
\hline Germany & 6 & 1 & 16.67 & 3 \\
\hline Netherlands & 4 & 3 & 75.00 & 3 \\
\hline Switzerland & 11 & 1 & 9.09 & 1 \\
\hline Total & 55 & 11 & 20.00 & 21 \\
\hline Total & 277 & 115 & 41.52 & 212 \\
\hline
\end{tabular}

sification of PT interventions based on the results of the cluster analysis. Pharmacotherapy, simple devices and self-care routines were excluded from the final categorization as they were reconsidered not to be PT interventions.

\subsection{Patterns describing how centers use PT interventions}

There are four patterns, which reflect how centers use PT interventions (four clusters of centers A-D, see Supplemental Fig. 1). Center clusters significantly differ in use of 25 PT interventions (Supplemental Table 4). Nevertheless, initial PT intervention categories are present in all clusters with similar proportions $(\mathrm{p}=0.061)$ (Supplemental Fig. 3).

While centers from one country were often assigned to the same cluster (Supplemental Fig. 2), and region membership differed significantly in clusters (Supplemental Table 3), the centers' cluster assignments did not fully align with the regions. Besides region, also center size, number and gender of physical therapists working in the center, and the average number of years therapists were qualified, played a role in the type of PT interventions utilized (Supplemental Table 5).

\section{Discussion}

Unpacking the black box of rehabilitation is a topic of particular importance. Whilst this has begun to be addressed in a number of different conditions such as stroke (Ballinger et al., 1999; DeJong et al., 2005), and brain injury (van Heugten et al., 2012) many questions remain unanswered. Results from this study contribute to broadening our understanding of the different PT interventions that are used in MS, as well as the context of their use.

The relatively high number of centers participating in this survey allows an extensive description of the situation in Europe. However, sample selection, questionnaire construction and other aspects should be considered in the data interpretation (Rasova et al., 2016).

\subsection{PT intervention used in $M S$}

Thirteen interventions are used by more than $75 \%$ of the centers. Although broadly different in their aims and content, common to each of these interventions is that there is an existing evidence base to support their effectiveness (Motl et al., 2017; Khan et al., 2007; Bansi et al., 2013; Hansen et al., 2015; Heine et al., 2015; Leone et al., 2015).

In contrast, the interventions used by less than $25 \%$ of centers, mostly confined to specific regions (Vojta reflex locomotion, Brunnstrom, Rood and Perfetti approaches, Brügger concept, Feldenkrais method, and Conductive education programme), are those where there is less robust scientific evidence available to support their effectiveness in MS. Thus far, evaluations of their effectiveness have predominantly been based on anecdotal experience. Whilst evidence to support the use of interventions such as Hippotherapy (Bronson et al., 2010) and Robotic- assisted rehabilitation (Schwartz et al., 2012; Feys, 2016) are increasing, these were reported to be used only rarely, probably because they are dependent on expensive equipment or environmental adjustments.

\subsection{Use of PT interventions depends on European region}

Thirteen interventions are used with significantly different frequency in the four regions. In North and West regions, fatigue management appears to be a routine standard of care, offered in almost all centers (Dalgas et al., 2010; Asano, 2014). Devices for walking are also used significantly more in these two regions. This suggests that these regions may place a greater emphasis and value on educating patients 
Table 3

Description of centers by regions.

\begin{tabular}{|c|c|c|c|c|c|c|}
\hline \multirow[t]{2}{*}{ Variables } & \multirow[t]{2}{*}{$\begin{array}{l}\text { Total (115 } \\
\text { centers) }\end{array}$} & \multicolumn{2}{|l|}{ Region } & & 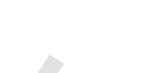 & \multirow[t]{2}{*}{ p-value } \\
\hline & & $\begin{array}{l}\text { East (16 } \\
\text { centers) }\end{array}$ & $\begin{array}{l}\text { North (37 } \\
\text { centers) }\end{array}$ & $\begin{array}{l}\text { South (51 } \\
\text { centers) }\end{array}$ & $\begin{array}{l}\text { West (11 } \\
\text { centers) }\end{array}$ & \\
\hline Number of respondents & $1.8( \pm 1.7)$ & $2.2( \pm 1.9)$ & $1.8( \pm 1.7)$ & $1.8( \pm 1.7)$ & $1.9( \pm 1.8)$ & 0.43 \\
\hline $\begin{array}{l}\text { Female gender } \\
\text { proportion } \\
\text { Size }\end{array}$ & $0.7( \pm 0.4)$ & $0.7( \pm 0.4)$ & $0.9( \pm 0.3)$ & $0.7( \pm 0.4)$ & $0.6( \pm 0.5)$ & $0.03^{*}$ \\
\hline $\begin{array}{l}\text { Small ( }<100 \text { patients/ } \\
\text { year) }\end{array}$ & $60(52.2 \%)$ & $7(43.8 \%)$ & $15(40.5 \%)$ & $34(66.7 \%)$ & $4(36.4 \%)$ & \\
\hline $\begin{array}{l}\text { Intermediate }(100-500 \mathrm{p} / \\
\text { y) }\end{array}$ & $45(39.1 \%)$ & $8(50.0 \%)$ & $18(48.6 \%)$ & $14(27.5 \%)$ & $5(45.5 \%)$ & \\
\hline $\begin{array}{l}\text { Large ( }>500 \text { patients/ } \\
\text { year) } \\
\text { MS ratio }\end{array}$ & $10(8.7 \%)$ & $1(6.2 \%)$ & $4(10.8 \%)$ & $3(5.9 \%)$ & $2(18.2 \%)$ & 0.18 \\
\hline General (up to $20 \% \mathrm{MS}$ ) & $81(70.4 \%)$ & $14(87.5 \%)$ & $26(70.3 \%)$ & $33(64.7 \%)$ & $8(72.7 \%)$ & \\
\hline Intermediate (20-80\% MS) & $12(10.4 \%)$ & $0(0.0 \%)$ & $4(10.8 \%)$ & $7(13.7 \%)$ & $1(9.1 \%)$ & \\
\hline Specialized ( $>80 \% \mathrm{MS}$ ) & $22(19.1 \%)$ & $2(12.5 \%)$ & $7(18.9 \%)$ & $11(21.6 \%)$ & $2(18.2 \%)$ & 0.74 \\
\hline \multicolumn{7}{|l|}{ MS Inpatient ratio } \\
\hline Outpatient ( $>80 \%$ out) & $47(40.9 \%)$ & $4(25.0 \%)$ & $10(27.0 \%)$ & $28(54.9 \%)$ & $5(45.5 \%)$ & \\
\hline Balanced (20-80\% out) & $49(42.6 \%)$ & $8(50.0 \%)$ & $19(51.4 \%)$ & $19(37.3 \%)$ & $3(27.3 \%)$ & \\
\hline Inpatient ( $<20 \%$ out $)$ & $19(16.5 \%)$ & $4(25.0 \%)$ & $8(21.6 \%)$ & $4(7.8 \%)$ & $3(27.3 \%)$ & 0.07 \\
\hline \multicolumn{7}{|l|}{ Max years of practice } \\
\hline $0-2$ & $11(9.6 \%)$ & $6(37.5 \%)$ & $0(0.0 \%)$ & $4(7.8 \%)$ & $1(9.1 \%)$ & \\
\hline $3-10$ & $32(27.8 \%)$ & $2(12.5 \%)$ & $6(16.2 \%)$ & $20(39.2 \%)$ & $4(36.4 \%)$ & \\
\hline$>10$ & $72(62.6 \%)$ & $8(50.0 \%)$ & $31(83.8 \%)$ & $27(52.9 \%)$ & $6(54.5 \%)$ & $<0.01 *$ \\
\hline \multicolumn{7}{|c|}{ Max worktime with MS patients } \\
\hline $0-24 \%$ & $49(42.6 \%)$ & $10(62.5 \%)$ & $13(35.1 \%)$ & $21(41.2 \%)$ & $5(45.5 \%)$ & \\
\hline $25-49 \%$ & $18(15.7 \%)$ & $2(12.5 \%)$ & $4(10.8 \%)$ & $9(17.6 \%)$ & $3(27.3 \%)$ & \\
\hline $50-74 \%$ & $20(17.4 \%)$ & $1(6.2 \%)$ & $8(21.6 \%)$ & $10(19.6 \%)$ & $1(9.1 \%)$ & \\
\hline $75-100 \%$ & $28(24.3 \%)$ & $3(18.8 \%)$ & $12(32.4 \%)$ & $11(21.6 \%)$ & $2(18.2 \%)$ & 0.61 \\
\hline \multicolumn{7}{|l|}{ Min education } \\
\hline $\mathrm{PhD}$ & $9(7.8 \%)$ & $1(6.2 \%)$ & $0(0.0 \%)$ & $8(15.7 \%)$ & $0(0.0 \%)$ & \\
\hline Masters & $35(30.4 \%)$ & $9(56.2 \%)$ & $12(32.4 \%)$ & $12(23.5 \%)$ & $2(18.2 \%)$ & \\
\hline Bachelor & $43(37.4 \%)$ & $4(25.0 \%)$ & $20(54.1 \%)$ & $12(23.5 \%)$ & $7(63.6 \%)$ & \\
\hline Diploma specialist & $19(16.5 \%)$ & $0(0.0 \%)$ & $3(8.1 \%)$ & $15(29.4 \%)$ & $1(9.1 \%)$ & \\
\hline Other education & $9(7.8 \%)$ & $2(12.5 \%)$ & $2(5.4 \%)$ & $4(7.8 \%)$ & $1(9.1 \%)$ & $<0.01 *$ \\
\hline
\end{tabular}

P-values smaller than 0.1 (borderline significance) are bold. Significant factors (p-value $<.05$ ) are marked with an asterisk.

on self-management approaches, and investing in rehabilitation devices, which can enhance people's mobility with minimal resources required in providing ongoing face-to-face PT sessions. Of note, the regions where emphasis on self-management is apparent, and ongoing face-to-face physiotherapy sessions are less commonly utilized, are the socio-economically wealthier countries.

For those countries sited within the Eastern region, the emphasis of PT is typically on one-to-one, face-to-face basis, using interventions such as Vojta reflex locomotion, Proprioceptive Neuromuscular Facilitation, Frankel's exercise, manual therapy, mechanotherapy or the Brügger concept. It is postulated that this may be related to the model of professional education and training adopted in Eastern Europe.

The survey results suggest that some symptoms are dealt with much more intensively in some regions than others. For example, in Eastern and Northern regions, pelvic floor exercise plays an important role, whereas its use is rarely reported in the Western and Southern regions.

\subsection{Seven clusters of PT interventions defined by use across European centers provided a basis for a a new categorization of PT interventions}

Cluster analysis identified seven clusters of PT interventions based on their use. For some clusters, the grouping corresponds with the initial classification provided by the PT core expert group. For example, cluster PTI-F and PTI-G correspond to task-oriented approaches (Supplemental Table 2, Figs. 3 and 4). For other clusters, combinations of two or more types of PT interventions have appeared, which seem to be complementary, or ideologically connected, for example Oriental, Hippotherapy, Aquatherapy, Nordic walking or Music therapy are usually offered together.
Based on the results of cluster analysis, and also taking into account the original categorization, the core group re-defined/re-named four categories of PT interventions (Supplemental Table 2, Figs. 3 and 4):

1. Physical activity (fitness/endurance/resistance) training (7 PT interventions, mostly in cluster PTI-C)

2. Neuroproprioceptive "facilitation, inhibition" (14 PT interventions, mostly in cluster PTI-A, and PTI-B) - interventions that were developed in the 1950s (for example PNF, Vojta reflex locomotion, Rood's Approach, Bobath, Brunnstrom approach)

3. Motor/skill acquisitions (individualized therapy led intervention) when the patient is increasingly active in the motor retraining process (15 PT interventions, mostly in cluster PTI-D, PTI-F and PTI-G)

4. Technology based (6 PT interventions cluster PTI-E).

4.4. Four patterns describing how centers use PT interventions (four clusters of centers)

Cluster analysis of centers identified four clusters. We offer the following description of the four clusters of centers based on significant differences of the PT interventions they use (Supplemental Table 4) and their description (Supplemental Table 5):

\subsubsection{Cluster $A$}

Cluster of centers who more frequently offer therapies targeted on physical fitness were mostly Southern centers with at least one experienced PT. This cluster comprises the highest ratio of large centers and 
Table 4

Use of PT interventions in centers by regions. PT interventions are ordered by the number of centers that use it.

\begin{tabular}{|c|c|c|c|c|c|c|}
\hline \multirow[t]{2}{*}{ Interventions } & \multirow[t]{2}{*}{ Total (115 centers) } & \multicolumn{4}{|l|}{ Region } & \multirow[t]{2}{*}{ p-value } \\
\hline & & East (16 centers) & North (37 centers) & South (51 centers) & West ( 11 centers $)$ & \\
\hline Balance & $113(98.3 \%)$ & $15(93.8 \%)$ & $37(100.0 \%)$ & $51(100.0 \%)$ & $10(90.9 \%)$ & 0.13 \\
\hline Transfer & $112(97.4 \%)$ & $14(87.5 \%)$ & $36(97.3 \%)$ & $51(100.0 \%)$ & $11(100.0 \%)$ & 0.12 \\
\hline Stretching & $109(94.8 \%)$ & $16(100.0 \%)$ & $37(100.0 \%)$ & $47(92.2 \%)$ & $9(81.8 \%)$ & 0.15 \\
\hline Aerobic & $103(89.6 \%)$ & $13(81.2 \%)$ & $36(97.3 \%)$ & $44(86.3 \%)$ & $10(90.9 \%)$ & 0.36 \\
\hline Strengthening & $101(87.8 \%)$ & $12(75.0 \%)$ & $37(100.0 \%)$ & $42(82.4 \%)$ & $10(90.9 \%)$ & 0.07 \\
\hline Self-care & $99(86.1 \%)$ & $10(62.5 \%)$ & $35(94.6 \%)$ & $44(86.3 \%)$ & $10(90.9 \%)$ & 0.07 \\
\hline Fatigue & $99(86.1 \%)$ & $10(62.5 \%)$ & $35(94.6 \%)$ & $43(84.3 \%)$ & $11(100.0 \%)$ & $0.04^{*}$ \\
\hline Breathing & $97(84.3 \%)$ & $14(87.5 \%)$ & $29(78.4 \%)$ & $46(90.2 \%)$ & $8(72.7 \%)$ & 0.43 \\
\hline Simple & $97(84.3 \%)$ & $15(93.8 \%)$ & $29(78.4 \%)$ & $43(84.3 \%)$ & $10(90.9 \%)$ & 0.55 \\
\hline Pain & $95(82.6 \%)$ & $12(75.0 \%)$ & $33(89.2 \%)$ & $40(78.4 \%)$ & $10(90.9 \%)$ & 0.52 \\
\hline Orthotics & $93(80.9 \%)$ & $9(56.2 \%)$ & $34(91.9 \%)$ & $41(80.4 \%)$ & $9(81.8 \%)$ & 0.07 \\
\hline Relaxation & $90(78.3 \%)$ & $15(93.8 \%)$ & $29(78.4 \%)$ & $37(72.5 \%)$ & $9(81.8 \%)$ & 0.44 \\
\hline Dual & $87(75.7 \%)$ & $9(56.2 \%)$ & $28(75.7 \%)$ & $41(80.4 \%)$ & $9(81.8 \%)$ & 0.36 \\
\hline Cognitive & $84(73.0 \%)$ & $11(68.8 \%)$ & $24(64.9 \%)$ & $41(80.4 \%)$ & $8(72.7 \%)$ & 0.52 \\
\hline Bobath & $82(71.3 \%)$ & $12(75.0 \%)$ & $22(59.5 \%)$ & $42(82.4 \%)$ & $6(54.5 \%)$ & 0.15 \\
\hline Daily & $80(69.6 \%)$ & $12(75.0 \%)$ & $23(62.2 \%)$ & $39(76.5 \%)$ & $6(54.5 \%)$ & 0.43 \\
\hline PNF & $79(68.7 \%)$ & $15(93.8 \%)$ & $17(45.9 \%)$ & $39(76.5 \%)$ & $8(72.7 \%)$ & $0.01 *$ \\
\hline Pelvic & $77(67.0 \%)$ & $14(87.5 \%)$ & $30(81.1 \%)$ & $27(52.9 \%)$ & $6(54.5 \%)$ & $0.03^{*}$ \\
\hline Stimulation & $76(66.1 \%)$ & $14(87.5 \%)$ & $23(62.2 \%)$ & $32(62.7 \%)$ & $7(63.6 \%)$ & 0.41 \\
\hline Proprioneuro & $75(65.2 \%)$ & $16(100.0 \%)$ & $19(51.4 \%)$ & $34(66.7 \%)$ & $6(54.5 \%)$ & $0.03^{*}$ \\
\hline Motor learning & $74(64.3 \%)$ & $9(56.2 \%)$ & $25(67.6 \%)$ & $32(62.7 \%)$ & $8(72.7 \%)$ & 0.79 \\
\hline Aquatherapy & $66(57.4 \%)$ & $8(50.0 \%)$ & $27(73.0 \%)$ & $24(47.1 \%)$ & $7(63.6 \%)$ & 0.17 \\
\hline Treadmill & $64(55.7 \%)$ & $8(50.0 \%)$ & $28(75.7 \%)$ & $20(39.2 \%)$ & $8(72.7 \%)$ & $0.02 *$ \\
\hline Manual & $62(53.9 \%)$ & $15(93.8 \%)$ & $12(32.4 \%)$ & $32(62.7 \%)$ & $3(27.3 \%)$ & $<0.01 *$ \\
\hline Biofeedback & $60(52.2 \%)$ & $10(62.5 \%)$ & $20(54.1 \%)$ & $27(52.9 \%)$ & $3(27.3 \%)$ & 0.43 \\
\hline Pharmacotherapy & $51(44.3 \%)$ & $3(18.8 \%)$ & $23(62.2 \%)$ & $19(37.3 \%)$ & $6(54.5 \%)$ & $0.05^{*}$ \\
\hline Nordic & $45(39.1 \%)$ & $10(62.5 \%)$ & $16(43.2 \%)$ & $13(25.5 \%)$ & $6(54.5 \%)$ & 0.07 \\
\hline Oriental & $44(38.3 \%)$ & $9(56.2 \%)$ & $14(37.8 \%)$ & $17(33.3 \%)$ & $4(36.4 \%)$ & 0.52 \\
\hline Cryotherapy & $38(33.0 \%)$ & $5(31.2 \%)$ & $9(24.3 \%)$ & $20(39.2 \%)$ & $4(36.4 \%)$ & 0.58 \\
\hline Mechanotherapy & $37(32.2 \%)$ & $13(81.2 \%)$ & $5(13.5 \%)$ & $15(29.4 \%)$ & $4(36.4 \%)$ & $<0.01 *$ \\
\hline Frenkel & $36(31.3 \%)$ & $8(50.0 \%)$ & $5(13.5 \%)$ & $22(43.1 \%)$ & $1(9.1 \%)$ & $0.01 *$ \\
\hline Gaming technology & $34(29.6 \%)$ & $2(12.5 \%)$ & $9(24.3 \%)$ & $17(33.3 \%)$ & $6(54.5 \%)$ & 0.17 \\
\hline Balance platform & $30(26.1 \%)$ & $7(43.8 \%)$ & $5(13.5 \%)$ & $15(29.4 \%)$ & $3(27.3 \%)$ & 0.20 \\
\hline Heat & $29(25.2 \%)$ & $8(50.0 \%)$ & $7(18.9 \%)$ & $11(21.6 \%)$ & $3(27.3 \%)$ & 0.17 \\
\hline Constraint & $29(25.2 \%)$ & $5(31.2 \%)$ & $8(21.6 \%)$ & $12(23.5 \%)$ & $4(36.4 \%)$ & 0.74 \\
\hline Music & $29(25.2 \%)$ & $6(37.5 \%)$ & $8(21.6 \%)$ & $12(23.5 \%)$ & $3(27.3 \%)$ & 0.73 \\
\hline Conductive & $26(22.6 \%)$ & $5(31.2 \%)$ & $4(10.8 \%)$ & $12(23.5 \%)$ & $5(45.5 \%)$ & 0.15 \\
\hline Robotic & $21(18.3 \%)$ & $7(43.8 \%)$ & $1(2.7 \%)$ & $9(17.6 \%)$ & $4(36.4 \%)$ & $0.01 *$ \\
\hline Perfetti & $20(17.4 \%)$ & $1(6.2 \%)$ & $0(0.0 \%)$ & $14(27.5 \%)$ & $5(45.5 \%)$ & 0.01 * \\
\hline Feldenkrais & $20(17.4 \%)$ & $5(31.2 \%)$ & $3(8.1 \%)$ & $11(21.6 \%)$ & $1(9.1 \%)$ & 0.22 \\
\hline Vojta & $19(16.5 \%)$ & $11(68.8 \%)$ & $1(2.7 \%)$ & $5(9.8 \%)$ & $2(18.2 \%)$ & $<0.01$ * \\
\hline Hippotherapy & $15(13.0 \%)$ & $2(12.5 \%)$ & $7(18.9 \%)$ & $4(7.8 \%)$ & $2(18.2 \%)$ & 0.55 \\
\hline Brunnstrom & $13(11.3 \%)$ & $4(25.0 \%)$ & $2(5.4 \%)$ & $6(11.8 \%)$ & $1(9.1 \%)$ & 0.36 \\
\hline Rood & $11(9.6 \%)$ & $1(6.2 \%)$ & $2(5.4 \%)$ & $8(15.7 \%)$ & $0(0.0 \%)$ & 0.36 \\
\hline Brügger & $10(8.7 \%)$ & $8(50.0 \%)$ & $0(0.0 \%)$ & $2(3.9 \%)$ & $0(0.0 \%)$ & $<0.01 *$ \\
\hline
\end{tabular}

A Use of Vojta intervention in centers by region

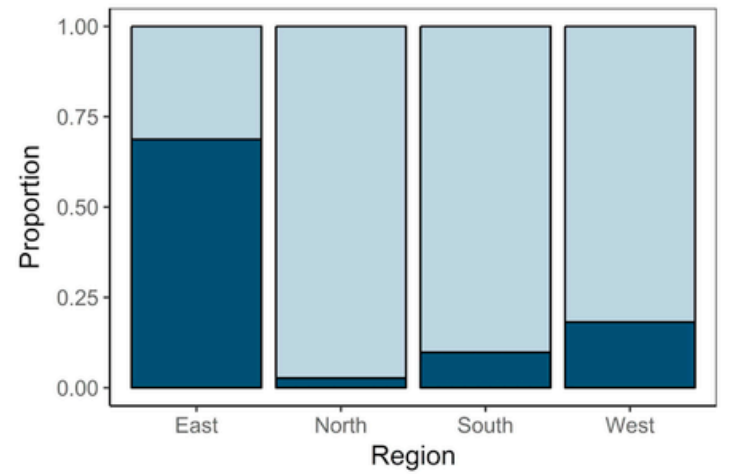

B Use of Fatigue intervention in centers by region

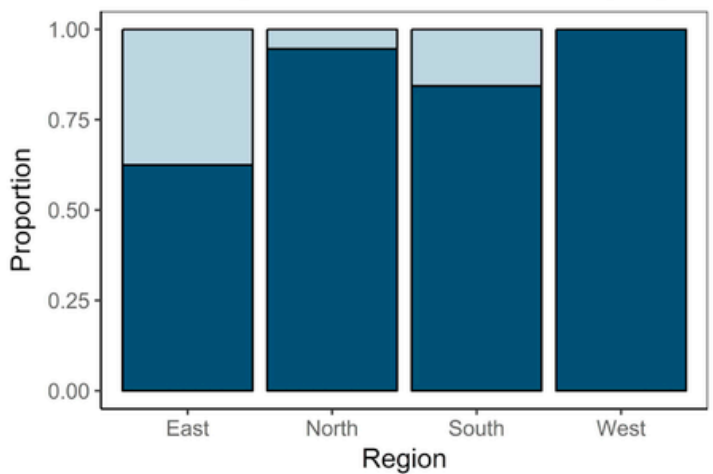

Center uses the intervention

Center does not use the intervention

Fig. 1. Proportion of interventions used in regions. A. Vojta intervention, B. Fatigue intervention. 


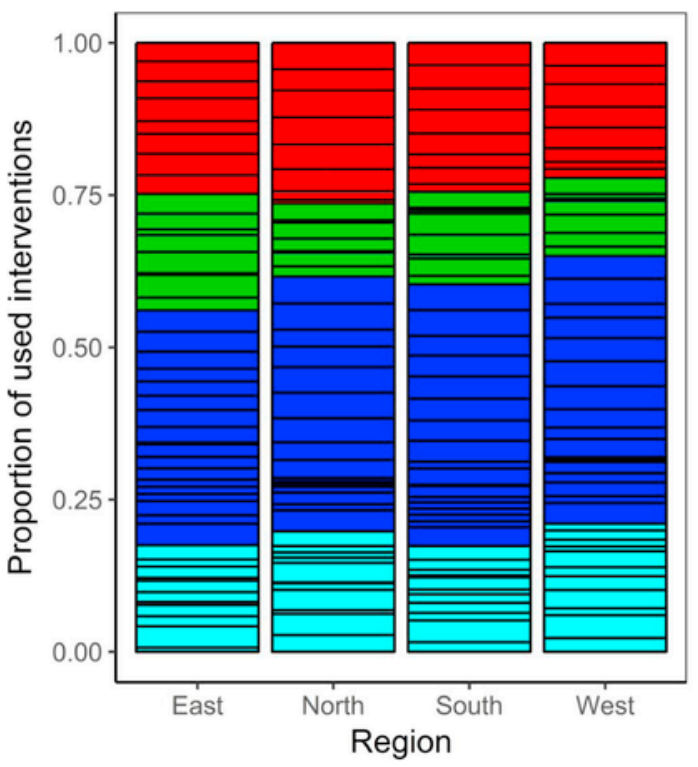

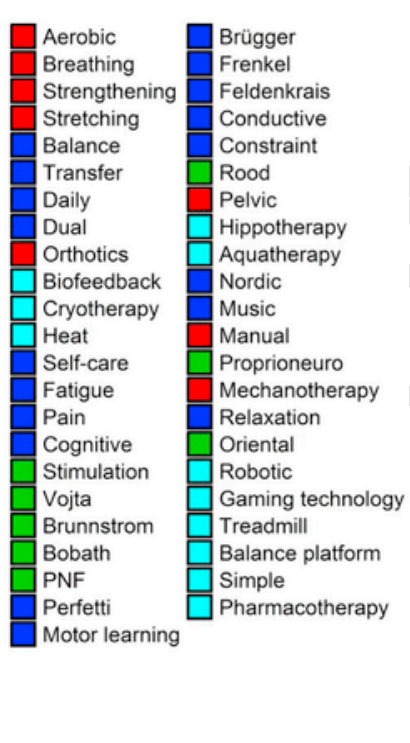

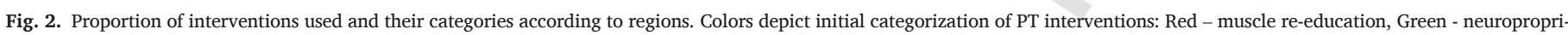
oceptive facilitation, Dark blue - task oriented approach, Light blue - use of special tools/devices.

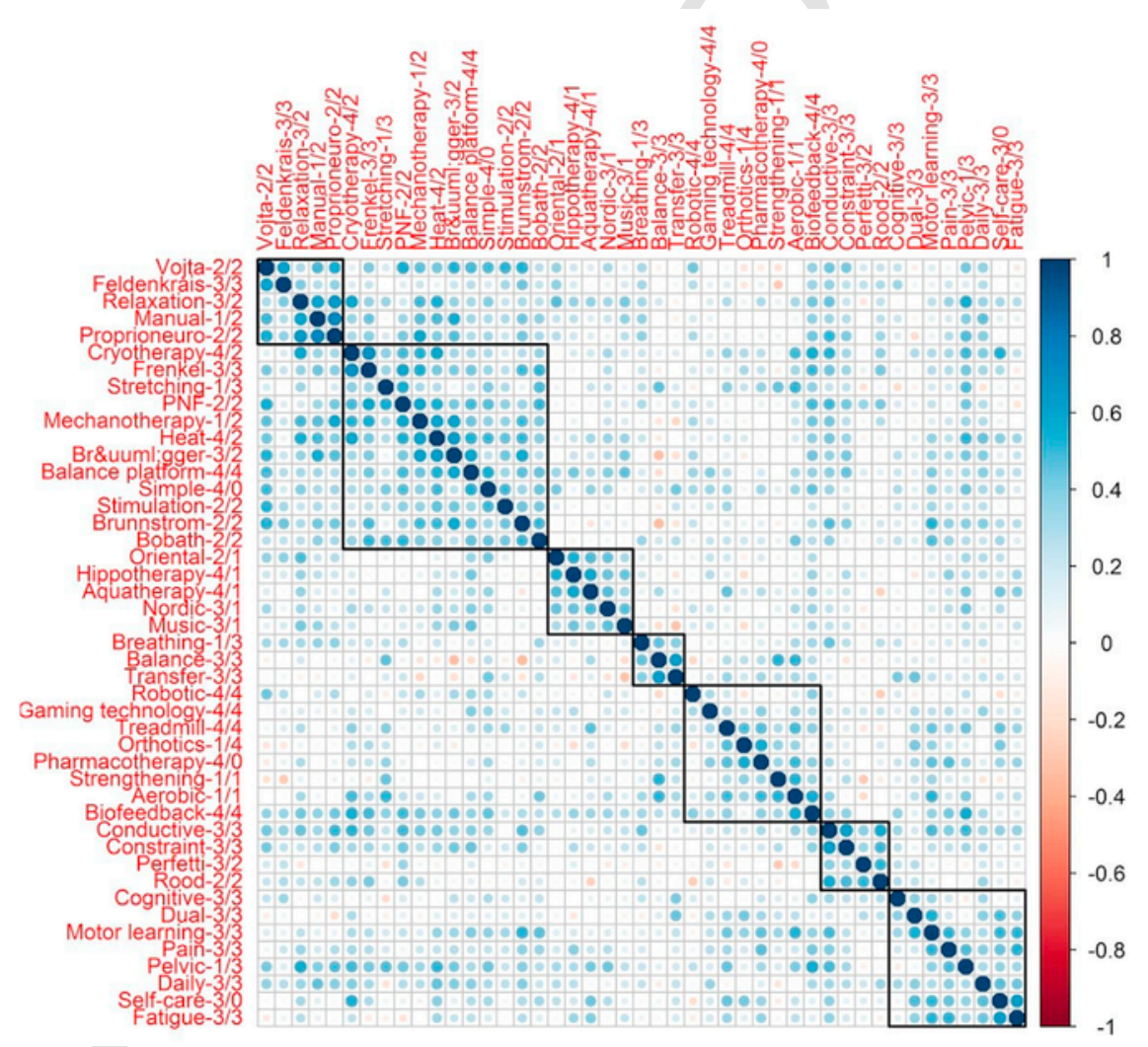

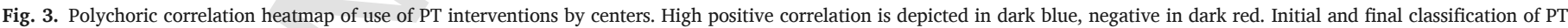
interventions is included next to intervention short name (see Supplemental Table 2).

of centers specialized in MS, and has the highest mean number of respondents (PTs) per center.

\subsubsection{Cluster B}

Centers in cluster B mostly offer interventions based on principles of neuroproprioceptive "facilitation, inhibition" approach. These are mostly small or intermediate centers in Eastern Europe, non-specialised in MS rehabilitation.

\subsubsection{Cluster $C$}

Cluster C more frequently provides gaming technology, special devices, proprioceptive posture therapy and robotic-assisted rehabilitation therapy. There are mainly small or intermediate centers from Western and Northern regions in this cluster. 


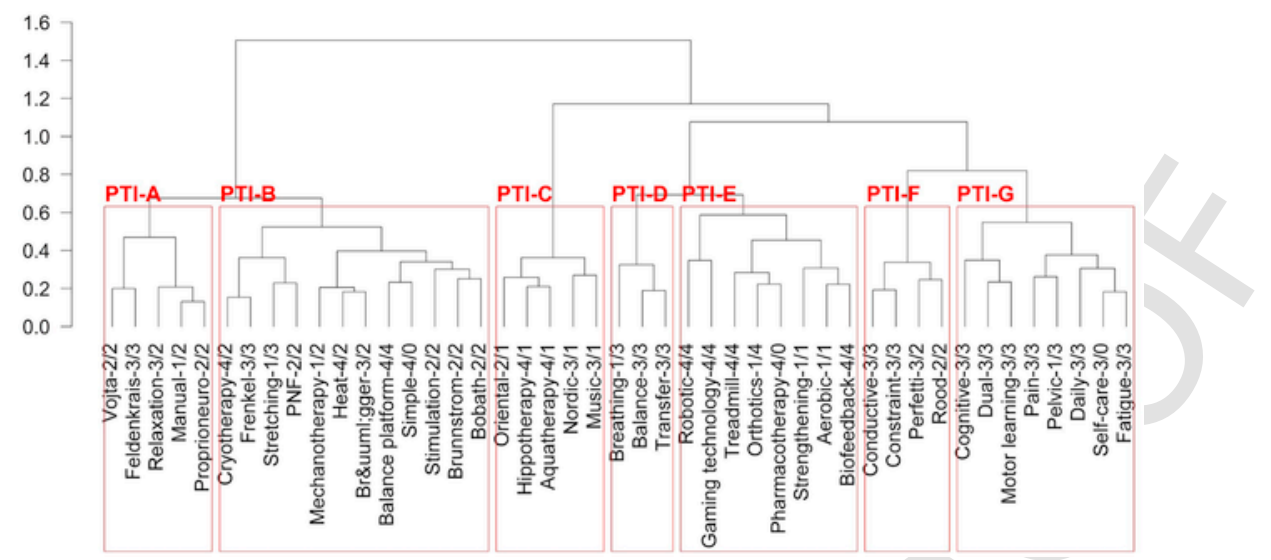

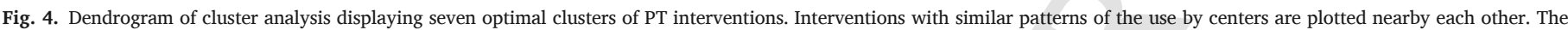

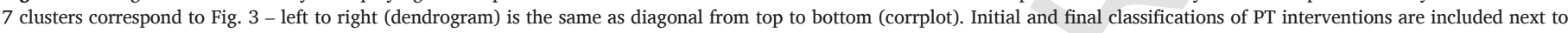
each intervention's short name (see Supplemental Table 2).

\subsubsection{Cluster D}

Cluster D generally offers a narrower variety of interventions and more frequently offers physical activity interventions such as hippotherapy, aquatherapy, oriental approaches etc. Cluster D was comprised mostly of small centers from Northern regions and has the highest ratio of female PT respondents.

\subsection{Study limitations}

There are some limitations of this study. The survey was carried out in English, however, participating countries differed in the PTs' knowledge of English language. Translation into different European languages might increase the response rate and provide results that are more precise. Also, some PT interventions may be known under different names in different regions. We tried to clarify the terminology by offering a description of the PT interventions (see Vocabulary in Supplemental Table 1 ). Moreover, it is recognized that the actual practice of applying the same PT interventions can differ in different places or when applied by different therapists. Offering more sources, e.g. videos and a list of relevant references might provide a helpful knowledge source for the PTs and increase the validity of the results. Finally, to improve the representativeness of the sample, use of a registry of physical therapists working with MS patients in Europe would be helpful. At the time the study was performed, however, no reliable registry was available to draw random samples from. Despite these limitations we believe this study provides important results and a platform for future research.

\section{Conclusions}

The responses of physical therapists about their use of interventions with MS patients do not provide evidence about the effectiveness of interventions. However, our research has confirmed that many of the PT interventions offered to MS patients are those that have the most robust scientific evidence to support their use. In order to change behavior in the use of PT interventions according to guidelines and evidence based medicine, it is essential to understand the reasons why certain interventions are applied; this is an important subject for future research. The analysis presented in this paper provides a unique opportunity to see how use of different PT interventions is related to region and other center characteristics, and moreover, which PT interventions are often offered together.

Cluster analysis of centers provided better understanding of what makes centers similar in the palette of the PT interventions that they offer. While center location plays a prominent role, other characteris- tics (number of PTs / center size, proportion of female PTs, PTs experience) were also found to be important for the description of centers using similar PT interventions. Personal connections and other factors also may influence which PT interventions are offered by the centers.

Cluster analysis based on use patterns provided the basis for a new classification of PT interventions. Even when considering the new classification, some clusters of PT interventions consisted of a mix of categories (Supplemental Table 2, Figs. 3 and 4, e.g. cluster PTI-B). Regional or historical aspects may have led to PT interventions of different types being clustered together. For example, the Feldenkrais method defined by the core group as a task oriented approach is often offered by the same centers that offer Vojta reflex locomotion which was defined as a facilitation approach (not so much with other facilitation methods), causing its classification into cluster PTI-A.

It is evident that the theoretical bases of the different interventions are partially overlapping and cannot in all cases be clearly separated from each other. Physical therapists are influenced in their choice of interventions by their clinical experience, intuition, and their knowledge of evidence based medicine. They sometimes combine different therapeutic approaches based on different theoretical models, with the aim of tailoring the intervention to provide a more effective and long lasting treatment to reduce impairments, and enhance the function, participation and well-being of their patients.

Understanding the factors that play a role in the use of PT interventions may lead to a better distribution of professional knowledge among countries and physical therapists working with persons with MS.

\section{Acknowledgements}

The survey was supported by a RIMS grant 2012 and unrestricted educational grant from Novartis Pharma AG to RIMS, 260388/SVV/2017 and Progres Q35.

\section{Disclosure of any conflicts of interest}

Authors declare no financial or non-financial conflict of interests.

\section{Authors' contributions}

All persons who meet authorship criteria are listed as authors, and all authors certify that they have participated sufficiently in the work to take public responsibility for the content, including participation in the concept, design, analysis, writing, or revision of the manuscript. The work is not under review elsewhere and has not been previously published. 


\section{Author's Note}

This research was partly conducted while P. Martinková was visiting University of Washington as a Fulbright-Masaryk fellow.

\section{Appendix A. Supporting information}

Supplementary data associated with this article can be found in the online version at doi:10.1016/j.msard.2018.03.005.

\section{References}

Dalgas, U., Stenager, E., Jakobsen, J., Petersen, T., Hansen, H.J., Knudsen, C., et al., 2010. Fatigue, mood and quality of life improve in MS patients after progressive resistance training. Mult. Scler. (Houndmills, Basingstoke, Engl.). 16 (4), 480-490.

Gijbels, D., Lamers, I., Kerkhofs, L., Alders, G., Knippenberg, E., Feys, P., 2011. The Armeo Spring as training tool to improve upper limb functionality in multiple sclerosis: a pilot study. J. Neuroeng. Rehabil. 8, 5 .

Freeman, J., Fox, E., Gear, M., Hough, A., 2012. Pilates based core stability training in ambulant individuals with multiple sclerosis: protocol for a multi-centre randomised controlled trial. BMC Neurol. 12, 19.

Carpinella, I., Cattaneo, D., Bertoni, R., Ferrarin, M., 2012. Robot training of upper limb in multiple sclerosis: comparing protocols with or without manipulative task components. IEEE Trans. Neural Syst. Rehabil. Eng.: a Publ. IEEE Eng. Med. Biol. Soc. 20 (3), 351-360.

Latimer-Cheung, A.E., Pilutti, L.A., Hicks, A.L., Martin Ginis, K.A., Fenuta, A.M., MacKibbon, K.A., et al., 2013. Effects of exercise training on fitness, mobility, fatigue, and health-related quality of life among adults with multiple sclerosis: a systematic review to inform guideline development. Arch. Phys. Med. Rehabil. 94 (9), 1800-1828, (e3).

Baert, I., Freeman, J., Smedal, T., Dalgas, U., Romberg, A., Kalron, A., et al., 2014. Responsiveness and clinically meaningful improvement, according to disability level, of five walking measures after rehabilitation in multiple sclerosis: a European multicenter study. Neurorehabilitation Neural Repair. 28 (7), 621-631.

Kjolhede, T., Vissing, K., de Place, L., Pedersen, B.G., Ringgaard, S., Stenager, E., et al., 2015. Neuromuscular adaptations to long-term progressive resistance training translates to improved functional capacity for people with multiple sclerosis and is maintained at follow-up. Mult. Scler. (Houndmills, Basingstoke, Engl.). 21 (5), 599-611.

Sandroff, B.M., Bollaert, R.E., Pilutti, L.A., Peterson, M.L., Baynard, T., Fernhall, B., et al., 2017. Multimodal exercise training in multiple sclerosis: a randomized controlled trial in persons with substantial mobility disability. Contemp. Clin. Trials 61, 39-47.

Heine, M., Verschuren, O., Hoogervorst, E.L., van Munster, E., Hacking, H.G., Visser-Meily, A., et al., 2017. Does aerobic training alleviate fatigue and improve societal participation in patients with multiple sclerosis? A randomized controlled trial. Mult. Scler. (Houndmills, Basingstoke, Engl.). 23 (11), 1517-1526.

Motl, R.W., Sandroff, B.M., Kwakkel, G., Dalgas, U., Feinstein, A., Heesen, C., et al., 2017. Exercise in patients with multiple sclerosis. Lancet Neurol. 16 (10), 848-856.

Khan, F., Pallant, J.F., 2007. Use of the International Classification of Functioning, Disability and Health (ICF) to identify preliminary comprehensive and brief core sets for multiple sclerosis. Disabil. Rehabil. 29 (3), 205-213.

Kesselring, J., Coenen, M., Cieza, A., Thompson, A., Kostanjsek, N., Stucki, G., 2008. Developing the ICF Core Sets for multiple sclerosis to specify functioning. Mult. Scler. (Houndmills, Basingstoke, Engl.). 14 (2), 252-254.

Rasova, K., Feys, P., Henze, T., van Tongeren, H., Cattaneo, D., Jonsdottir, J., et al., 2010. Emerging evidence-based physical rehabilitation for multiple sclerosis-towards an inventory of current content across Europe. Health Qual. Life Outcomes 8, 76.
Rasova, K., Freeman, J., Martinkova, P., Pavlikova, M., Cattaneo, D., Jonsdottir, J., et al., 2016. The organisation of physiotherapy for people with multiple sclerosis across Europe: a multicentre questionnaire survey. BMC Health Serv. Res. 16 (1), 552.

Rasova, K., Martinkova, P., Cattaneo, D., Jonsdottir, J., Henze, T., Baert, I., et al., 2014. Physical therapy in multiple sclerosis differs across Europe: information regarding an ongoing study. J. Int Med Res. 42, 1185.

Shumway-Cook, A., 2006. WMH. Motor Control: Translating Research into Clinical Practice. Lippincott Williams\& Wilkins, London.

Department UNS. Composition of macro geographical (continental) regions, geographical sub-regions, and selected economic and other groupings 〈http://unstats.un.org/unsd/ methods/m49/m49regin.htm $\rangle$ [.

Ward, J.H., 1963. Hierarchical grouping to optimize an objective function. J. Am. Stat. Assoc. $58,236-244$.

Mardia, K.V.K.J., Bibby, J.M., 1979. Multivariate Analysis. Academic Press, London-New York-Toronto-Sydney-San Francisco.

BD VWaR, 2002. Modern Applied Statistics with S. Springer, New York.

Hope, A.C., 1968. A simplified Monte Carlo significance test procedure. J. R. Stat. Soc. Ser. B (Methodol.) 30 (3), 582-598.

B $\mathrm{H}, 1995$. Controlling the false discovery rate: a practical and powerful approach to hultiple testing. J. R. Stat. Soc. Ser. B Stat. Methodol. 57 (1), 289-300.

A A, 2013. Categorical Data Analysis, 3rd ed Wiley, New Jersey.

Team, R.C., 2017. R: a language and environment for statistical computing. R Foundation for Statistical Computing, Vienna, Austria.

Ballinger, C., Ashburn, A., Low, J., Roderick, P., 1999. Unpacking the black box of therapy -- a pilot study to describe occupational therapy and physiotherapy interventions for people with stroke. Clin. Rehabil. 13 (4), 301-309.

DeJong, G., Horn, S.D., Conroy, B., Nichols, D., Healton, E.B., 2005. Opening the black box of post-stroke rehabilitation: stroke rehabilitation patients, processes, and outcomes. Arch. Phys. Med. Rehabil. 86 (12Suppl 2), S1-s7.

van Heugten, C., Gregorio, G.W., Wade, D., 2012. Evidence-based cognitive rehabilitation after acquired brain injury: a systematic review of content of treatment. Neuropsychol. Rehabil. 22 (5), 653-673.

Khan, F., Turner-Stokes, L., Ng, L., Kilpatrick, T., 2007. Multidisciplinary rehabilitation for adults with multiple sclerosis. Cochrane Database Syst. Rev. (2)), Cd006036.

Bansi, J.B.W., Gamper, U., Kesselring, J., 2013. Training in MS: influence of two different endurance training protocols (aquatic versus overland) on cytokine and neurotrophin concentrations during three week randomized controlled trial. Mult. Scler. 19 (5), 613-621.

Hansen, D., Wens, I., Keytsman, C., Eijnde, B.O., Dendale, P., 2015. Is long-term exercise intervention effective to improve cardiac autonomic control during exercise in subjects with multiple sclerosis? A randomized controlled trial. Eur. J. Phys. Rehabil. Med. 51 (2), 223-231.

Heine, M., van den Akker, L.E., Verschuren, O., Visser-Meily, A., Kwakkel, G., 2015. Reliability and responsiveness of cardiopulmonary exercise testing in fatigued persons with multiple sclerosis and low to mild disability. PloS One 10 (3), e0122260.

Leone, C., Severijns, D., Dolezalova, V., Baert, I., Dalgas, U., Romberg, A., et al., 2015. Prevalence of walking-related motor fatigue in persons with multiple sclerosis: decline in walking distance induced by the 6-minute walk test. Neurorehabilitation Neural Repair.

Bronson, C., Brewerton, K., Ong, J., Palanca, C., Sullivan, S.J., 2010. Does hippotherapy improve balance in persons with multiple sclerosis: a systematic review. Eur. J. Phys. Rehabil. Med. 46 (3), 347-353.

Schwartz, I., Sajin, A., Moreh, E., Fisher, I., Neeb, M., Forest, A., et al., 2012. Robot-assisted gait training in multiple sclerosis patients: a randomized trial. Mult. Scler. (Houndmills, Basingstoke, Engl.). 18 (6), 881-890.

Feys, P., 2016. Potential of robot-assisted therapy for disabled persons with MS. Mult. Scler. (Houndmills, Basingstoke, Engl.). 22 (3), 264-265.

Asano, M.F.M., 2014. Meta-analysis of three different types of fatigue management interventions for people with multiple sclerosis: exercise, education, and medication. Mult. Scler. Int 798285. 